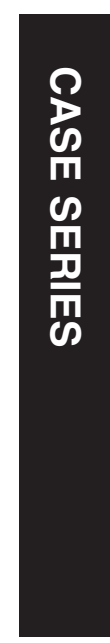

Department of

Ophthalmology, The Jules

Stein Eye Institute,

University of California,

Los Angeles, Los Angeles,

CA, USA

Correspondence:

TA McCannel, Department of Ophthalmology, The Jules Stein Eye Institute, University of California, Los Angeles, 100 Stein Plaza, Los Angeles, CA 90095, USA

Tel: + 13102067484

Fax: + 13107947904

E-mail: tmccannel@jsei.ucla. edu

Received: 13 March 2013 Accepted in revised form: 5 May 2013

Published online: 7 June 2013

\section{Post-brachytherapy tumor endoresection for treatment of toxic maculopathy in choroidal melanoma}

\author{
Abstract \\ Purpose Toxic tumor syndrome may occur \\ when the irradiated choroidal melanoma \\ releases cytokines, by exudation from \\ irradiated ischemic tissue. We report our \\ experience and outcomes in a series of post- \\ brachytherapy tumor endoresection to \\ mediate radiation complications. \\ Methods Patients who underwent \\ endoresection of a choroidal melanoma \\ treated with iodine-125 plaque brachytherapy \\ were evaluated. Baseline patient and tumor \\ parameters were tabulated. \\ Results Five patients underwent post- \\ brachytherapy tumor endoresection with \\ intraocular gas or silicone oil tamponade. \\ Three of the five patients underwent \\ concomitant phacoemulsification with \\ intraocular lens placement. Initial tumor \\ height ranged from $2.03-8.91 \mathrm{~mm}$ (mean \\ $5.81 \mathrm{~mm}$ ). Time between brachytherapy and \\ endoresection ranged from 13-62 months \\ (mean 26.8 months), and total follow-up time \\ from brachytherapy ranged from 2.5-9.75 years \\ (mean 5.2 years). Vision post-brachytherapy \\ and pre-endoresection ranged from 20/30 to \\ $20 / 400$. Final visual acuity ranged from $20 / 70$ \\ to no light perception. One patient developed \\ neovascular glaucoma. Radiation maculopathy \\ increased in all patients. One patient \\ developed metastasis at last follow-up. No \\ patient developed exudative retinal \\ detachment, none had local treatment failure, \\ and none required enucleation. \\ Conclusion Although tumor endoresection \\ post-brachytherapy is a technically feasible \\ procedure, all patients in our series \\ experienced progressive radiation \\ maculopathy with gradual visual decline.
}

TA McCannel

Eye (2013) 27, 984-988; doi:10.1038/eye.2013.115; published online 7 June 2013

Keywords: choroidal melanoma; uveal melanoma; endoresection; radiation retinopathy; brachytherapy; toxic tumor

\section{Introduction}

Radiation maculopathy post-brachytherapy is the primary cause of irreversible vision loss in patients with choroidal melanoma. ${ }^{1-3}$ Treatments with laser photocagulation,, 4 steroids, ${ }^{6-8}$ and anti-vascular endothelial growth factor agents ${ }^{9-12}$ do not offer a long-term solution.

Ischemia and exudative retinal detachment following the irradiation of large tumors has been described by Damato and others ${ }^{13,14}$ to be a result of 'toxic tumor syndrome'. This may involve the release of inflammatory cytokines, exudation from irradiated and incompetent vessels, and vascular endothelial growth factor from ischemic tissue. Transscleral local resection of residual tumor in patients with exudative retinal detachment and neovascular glaucoma following radiation may result in resolution of these complications by removing the source of toxic inflammatory mediators, which may contribute to the progression of maculopathy.

\section{Materials and methods}

The study was approved by the Institutional Review Board of the University of California, Los Angeles. The records of all patients with clinical diagnosis of choroidal melanoma treated with iodine-125 plaque brachytherapy 
who had tumor endoresection via pars plana vitrectomy were reviewed. All patients who had undergone tumor endoresection, had ultrasonographic evidence of tumor regression, and had expected radiation retinopathy were included. Surgeries were performed by the author.

Details of the radioactive plaque placement procedure have been described. ${ }^{15-17}$ Tumor endoresection was performed via a pars plana 20 gauge vitrectomy approach. In phakic cases, phacoemulsification with intraocular lens placement was performed in combination with vitrectomy, which included complete vitreous removal to the ora serrata. Endolaser was applied to the base of the tumor. The tumor and overlying retina were removed with the vitreous cutter to bare sclera. Intraocular cautery and elevation of intraocular pressure were used to achieve hemostasis. C3F8 gas or Silicone Oil 5000 centistokes was used for endotamponade.

\section{Case reports}

\section{Case 1}

A 36-year-old male with 20/20 vision was treated for a 6-mm choroidal melanoma. (See Table 1 for pre-plaque and pre-endoresection characteristics). After 5.2 years (62 months), his vision declined to $20 / 80$ with exudates and cystoid macular edema, and foveal capillary drop-out on fluorescein angiography. At 4.42 years (53 months) after endoresection with C3F8 gas, the vision was 20/125, and there was cystoid edema, exudates, and hemorrhage in the macula. (See Table 2 for patient characteristics at final follow-up).

\section{Case 2}

A 50-year-old male with counting fingers vision was treated for a 8.13-mm choroidal melanoma. After 2.1 years (25 months), his vision declined to 20/400 with exudates and cystoid macular edema. At 3.83 years (46 months) after combined cataract surgery and endoresection with silicone oil, the vision was no light perception, and there was diffuse cystoid edema, exudates, and vascular sclerosis of the retina. $\mathrm{He}$ developed metastasis of the lungs and liver.

\section{Case 3}

A 68-year-old male with $20 / 30$ vision was treated for a 2.03-mm choroidal melanoma. After 1.1 years (13 months), his vision was 20/25 with fluorescein angiographic macular edema. Two years (24 months) after endoresection with C3F8 gas, the vision was 20/70,

Table 1 Patient characteristics pre-plaque and pre-endoresection

\begin{tabular}{|c|c|c|c|c|c|c|c|c|c|}
\hline \multirow[t]{2}{*}{ Case } & \multirow[t]{2}{*}{ Sex } & \multirow{2}{*}{$\begin{array}{c}\text { Age } \\
\text { (years) }\end{array}$} & \multirow{2}{*}{$\begin{array}{c}\text { Initial } \\
V A\end{array}$} & \multirow{2}{*}{$\begin{array}{c}\text { Tumor } \\
\text { height }(\mathrm{mm})\end{array}$} & \multirow{2}{*}{$\begin{array}{c}\text { Time to } \\
\text { endoresection } \\
\text { years (months) }\end{array}$} & \multirow{2}{*}{$\begin{array}{c}\text { Pre- } \\
\text { endoresection } \\
V A\end{array}$} & \multirow{2}{*}{$\begin{array}{l}\text { Pre-endoresection } \\
\text { tumor height }(\mathrm{mm})\end{array}$} & \multicolumn{2}{|c|}{ Macula status pre-endoresection } \\
\hline & & & & & & & & Clinical & $F A$ \\
\hline 1 & $\mathrm{M}$ & 36 & $20 / 20$ & 6 & $5.2(62)$ & $20 / 80$ & 1.93 & CME, exudates & Mild ischemia \\
\hline 2 & M & 50 & $\mathrm{CF}$ & 8.13 & $2.1(25)$ & $20 / 400$ & 7.51 & CME, exudates & $\mathrm{N} / \mathrm{A}$ \\
\hline 3 & $\mathrm{M}$ & 68 & $20 / 30$ & 2.03 & $1.1(13)$ & $20 / 25$ & 2.17 & Normal & CME \\
\hline 4 & M & 42 & $20 / 25$ & 8.91 & $1.25(15)$ & $20 / 30$ & 6.5 & Normal & Mild ischemia \\
\hline
\end{tabular}

Abbreviations: CME, cystoid macular edema; FA, fluorescein angiogram; N/A, not available; VA, visual acuity.

${ }^{\text {a }}$ Patient had advanced cataract.

Table 2 Patient characteristics at final follow-up

\begin{tabular}{lccccccc}
\hline Case & Endo surgery & $\begin{array}{c}\text { Total follow-up } \\
\text { years (months) }\end{array}$ & $\begin{array}{c}\text { Exudative } \\
\text { RD }\end{array}$ & NVG & Final VA & Final macular status & Metastasis \\
\hline 1 & PPV C3F8 & $9.75(117)$ & No & No & $20 / 125$ & Diffuse CME, exudates, hemes & No \\
2 & Phaco PPV SiO & $5.92(71)$ & No & No & NLP & Diffuse CME, exudates, vasc sclerosis & Yes \\
3 & PPV C3F8 & $3.08(37)$ & No & No & $20 / 70$ & Moderate CME, exudates, hemes & No \\
4 & Phaco PPV C3F8 & $4.75(57)$ & No & Yes & CF & Diffuse CME, exudates, hemes & No \\
5 & Phaco PPV C3F8 & $2.5(30)$ & No & No & CF & Diffuse CME, exudates, hemes & No \\
\hline
\end{tabular}

Abbreviations: CF, counting fingers; CME, cystoid macular edema; Endo, endoresection; hemes, retinal hemorrhages; NLP, no light perception; NVG, neovascular glaucoma; phaco, phacoemulsification; PPV, pars plana vitrectomy; RD, retinal detachment; SiO, silicone oil 5000 centistokes; VA, visual acuity; vasc, vascular; $\mathrm{C} 3 \mathrm{~F} 8$, perfluoropropane gas. 
and there was moderate cystoid edema, exudates, and hemorrhage of the macula.

\section{Case 4}

A 42-year-old male with 20/25 vision was treated for a 8.91-mm choroidal melanoma with good tumor response to treatment (Figure 1). After 1.25 years (15 months), his vision was 20/30 with mild foveal capillary drop-out on fluorescein angiography. At 3.5 years (42 months) after combined cataract surgery and endoresection with C3F8 gas, the vision was counting fingers. He had diffuse cystoid edema, exudates, and hemorrhage of the macula (Figure 2). Three and a half years following

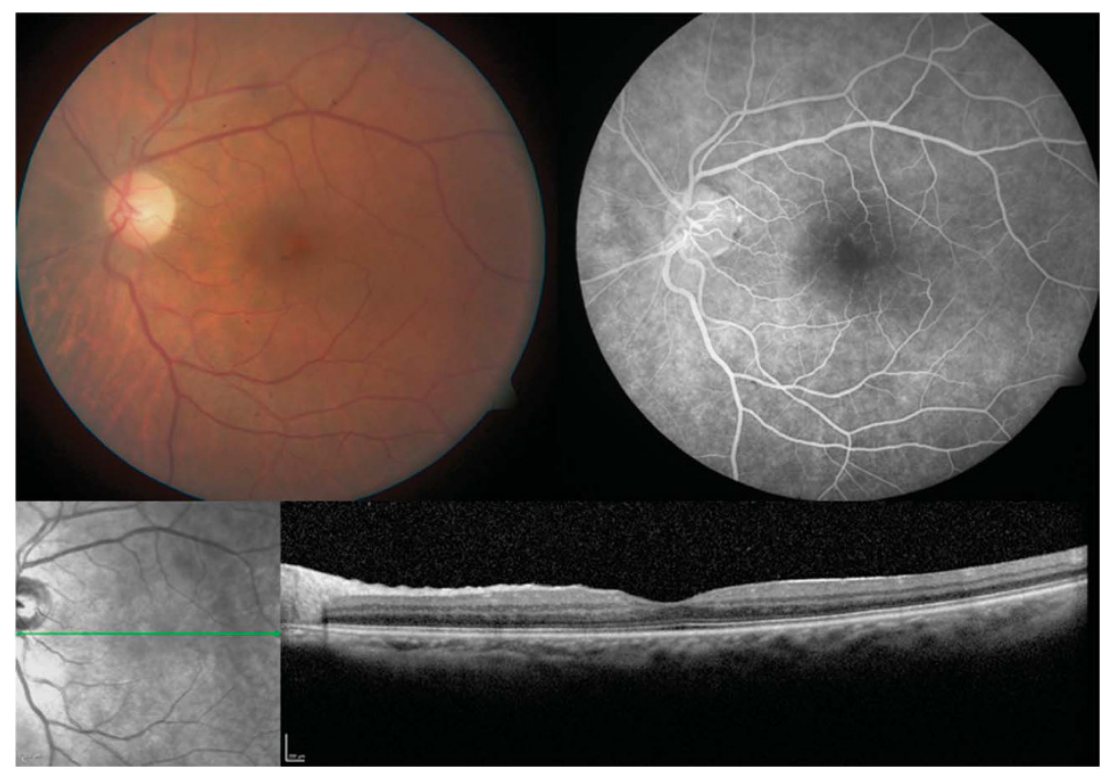

Figure 1 Macular photograph and mid-phase fluorescein angiogram 15 months after iodine-125 plaque brachytherapy for a 8.91-mm choroidal melanoma located in the inferonasal equatorial fundus (tumor not shown). Angiogram reveals foveal capillary drop-out. Ocular coherence tomography reveals trace thinning of the outer plexiform layer at the fovea. Vision is 20/30 (Case 4).

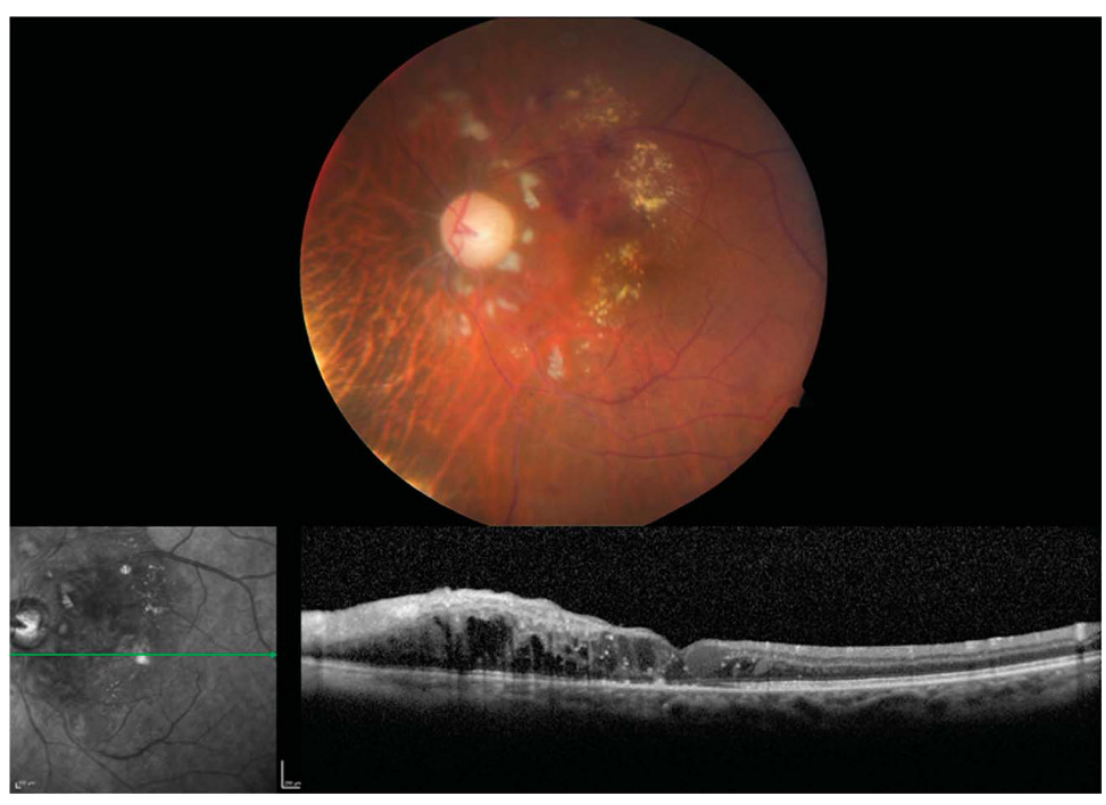

Figure 2 Macular photograph of same patient demonstrating typical features of radiation maculopathy: exudates, peripapillary nerve fiber layer infarcts, retinal hemorrhages, and disk pallor 26 months (2.17 years) after tumor endoresection (41 months (3.42 years) after brachytherapy). Ocular coherence tomography reveals disorganization of photoreceptor outer segments, intraretinal fluid and exudates worse on the nasal side. Vision is counting fingers. 
endoresection surgery, he developed neovascular glaucoma, which was successfully controlled with panretinal laser photocoagulation and intravitreal bevacizumab injections.

\section{Case 5}

A 60 -year-old female with 20/25 vision was treated for a 3.97-mm choroidal melanoma with good tumor response to treatment. After 1.6 years (19 months), her vision declined to 20/60 with advanced nuclear sclerotic cataract. At 11 months after combined cataract and endoresection with C3F8 gas, the vision was counting fingers, and there was diffuse cystoid edema, exudates, and hemorrhage of the macula.

\section{Discussion}

The aim of this report was to evaluate the feasibility and outcomes of five cases where post-brachytherapy tumor endoresection was performed with mild signs of radiation retinopathy. There were no surgical complications. Over the 2.9 years (35.2 months), average follow-up after endoresection, clinical signs of radiation retinopathy progressed, and vision continued to deteriorate.

Based on the 'toxic tumor syndrome' theory, we expected that debulking the residual-treated melanoma, while the visual acuity and macular status were minimally affected, might limit progression of radiation retinopathy. One could consider that the deterioration in vision might have been worse without endoresection. Endoresection post-irradiation of large tumors has been reported to resolve serous retinal detachment and neovascular glaucoma. ${ }^{13,14}$ None of the cases in our series developed serous exudation. However, Case 4 developed neovascular glaucoma despite postbrachytherapy endoresection.

In summary, post-brachytherapy tumor endoresection is a technically feasible procedure. As macular status and vision continued to deteriorate after endoresection in this series, endoresection alone may not be sufficient to improve visual outcomes.

\section{Summary}

\section{What was known before}

- Toxic tumor syndrome may be helpful to debulk cytokines in the irradiated choroidal melanoma, which drive radiation retinopathy.

\section{What this study adds}

- We found that radiation retinopathy increased and vision declined despite tumor endoresection after an average follow-up interval of 5 years.

\section{Conflict of interest}

The author declares no conflict of interest.

\section{Acknowledgements}

This study was supported by an unrestricted grant from Research to Prevent Blindness and the George E. and Ruth Moss Trust. The author has full control of all primary data and agrees data review upon request.

\section{References}

1 Melia BM, Abramson DH, Albert DM, Boldt HC, Earle JD, Hanson WF et al. Collaborative ocular melanoma study (COMS) randomized trial of I-125 brachytherapy for medium choroidal melanoma. I. Visual acuity after 3 years COMS report no. 16. Ophthalmology 2001; 108: 348-366.

2 Quivey JM, Char DH, Phillips TL, Weaver KA, Castro JR, Kroll SM. High intensity 125-iodine (125I) plaque treatment of uveal melanoma. Int J Radiat Oncol Biol Phys 1993; 26: 613-618.

3 Gündüz K, Shields CL, Shields JA, Cater J, Freire JE, Brady LW. Radiation retinopathy following plaque radiotherapy for posterior uveal melanoma. Arch Ophthalmol 1999; 117: 609-614.

4 Hykin PG, Shields CL, Shields JA, Arevalo JF. The efficacy of focal laser therapy in radiation-induced macular edema. Ophthalmology 1998; 105: 1425-1429.

5 Finger PT, Kurli M 2005; Laser photocoagulation for radiation retinopathy after ophthalmic plaque radiation therapy. Br J Ophthalmol 89: 730-738.

6 Shields CL, Demirci H, Dai V, Marr BP, Mashayekhi A, Materin MA et al. Intravitreal triamcinolone acetonide for radiation maculopathy after plaque radiotherapy for choroidal melanoma. Retina 2005; 25: 868-874.

7 Sutter FK, Gillies MC. Intravitreal triamcinolone for radiation-induced macular edema. Arch Ophthalmol 2003; 121: 1491-1493.

8 Horgan N, Shields CL, Mashayekhi A, Teixeira LF, Materin $\mathrm{MA}, \mathrm{O}^{\prime}$ Regan $\mathrm{M}$ et al. Periocular triamcinolone for prevention of macular edema after iodine 125 plaque radiotherapy of uveal melanoma. Retina 2008; 28: 987-995.

9 Mason JO, Albert Jr., MA, Persaud TO, Vail RS. Intravitreal bevacizumab treatment for radiation macular edema after plaque radiotherapy for choroidal melanoma. Retina 2007; 27: 903-907.

10 Finger PT. Radiation retinopathy is treatable with antivascular endothelial growth factor bevacizumab (Avastin). Int J Radiat Oncol Biol Phys 2008; 70: 974-977.

11 Finger PT, Chin K. Anti-vascular endothelial growth factor bevacizumab (avastin) for radiation retinopathy. Arch Ophthalmol 2007; 125: 751-756.

12 Gupta A, Muecke JS. Treatment of radiation maculopathy with intravitreal injection of bevacizumab (Avastin). Retina 2008; 28: 964-968.

13 Damato BE, Foulds WS. Surgical Resection of Choroidal Melanoma. In: Ryan SJ (ed.). Retina, Vol. 1, Basic Science, Inherited Retinal Disease and Tumors, 4th edn. CV Mosby: St. Louis, 2005 (Chapter 40). 
14 Singh AD, Damato BE, Pe'er J, Murphree AL, Perry JD. Management of Patients with Uveal Melanoma. Essential Ophthal Oncol 2009; 39: p93.

15 Young TA, Rao NP, Glasgow BJ, Moral JN, Straatsma BR Fluorescent in situ hybridization for monosomy 3 via 30gauge fine-needle aspiration biopsy of choroidal melanoma in vivo. Ophthalmology 2007; 114: 142-146.
16 Young TA, Burgess BL, Rao NP, Glasgow BJ, Straatsma BR. Transscleral fine-needle aspiration biopsy of macular choroidal melanoma. Am J Ophthalmol 2008; 145: 297-302.

17 McCannel TA, Burgess BL, Nelson SF, Eskin A, Straatsma BR. Genomic identification of significant targets in ciliochoroidal melanoma. Invest Ophthalmol Vis Sci 2011; 52: 3018-3022. 